\title{
Why kidneys fail post-partum: a tubulocentric viewpoint
}

Patricia Villie $^{1}$ - Marc Dommergues ${ }^{2}$ - Isabelle Brocheriou ${ }^{3,4}$. Giorgina Barbara Piccoli ${ }^{5,6}$ Jérôme Tourret ${ }^{4}$.

Alexandre Hertig ${ }^{1,4}$

\begin{abstract}
Kidneys may fail post-partum in a number of circumstances due, for example, to post-partum haemorrhage, preeclampsia, amniotic fluid embolism or septic abortion. All these conditions in pregnancy and post partum represent a threat not only to the endothelium but also to the renal tubular epithelium, and as such may lead to rapid and also irreversible impairment of the renal function. This paper is a non-systematic review of the literature and of our experience, in which we discuss the main open issues on kidney disease in pregnancy and following delivery, in particular as regards tubular damage, with the aim to help reasoning on acute kidney injury (AKI) following delivery. The review will emphasize the often under-estimated importance of the tubular epithelium in the peri-partum period and will: (1) describe the main characteristics of the renal tissues around delivery; (2) define pregnancy-related AKI according to recent Kidney Disease/Improving Global Outcome (KDIGO) guidelines; (3) discuss the most common circumstances of post-partum AKI; and (4) describe the input expected from urinalysis, renal imaging and kidney biopsy.
\end{abstract}

Keywords Acute kidney injury $\cdot$ Acute tubular necrosis $\cdot$ Pregnancy $\cdot$ Preeclampsia $\cdot$ Post-partum haemorrhage $\cdot$ sFlt-1 PlGF

\section{Abbreviations \\ AKI Acute kidney injury \\ ATN Acute tubular necrosis \\ RBP Retinol-binding protein \\ sEng Soluble endoglin \\ s-Flt1 Soluble fms-like tyrosine kinase 1 \\ TMA Thrombotic microangiopathy \\ VEGF Vascular endothelial growth factor}

Alexandre Hertig

alexandre.hertig@sorbonne-universite.fr

1 APHP, Hôpital Tenon, Urgences Néphrologiques et Transplantation Rénale, 4 rue de la Chine, 75020 Paris, France

2 Department of Gynecology and Obstetrics, APHP, Groupe Hospitalier La Pitié Salpêtrière Charles Foix, Paris, France

3 Department of Pathology, APHP, Hôpital Tenon, Paris, France

4 Sorbonne Universités, UPMC Université Paris 06, UMR_S 1155, 75005 Paris, France

5 Centre Hospitalier du Mans Le Mans, Le Mans, France

6 Department of Clinical and Biological Sciences, University of Torino, Turin, Italy

\section{Introduction: the kidney at the end of pregnancy}

Maternal endothelium is exposed physiologically to placenta-produced anti-angiogenic factors. Among the most popular and best characterized, are the soluble forms of fms-like tyrosine kinase 1 (sFlt-1) and of endoglin (sEng) $[1,2]$. In the mother, sFlt- 1 acts by capturing placental growth factor (PlGF), produced by the placenta, and free vascular endothelial growth factor (VEGF), a cytokine continuously provided by the adjacent podocytes [3]. As with all fenestrated endothelia, the glomerular capillary is critically dependent on VEGF [4]. During preeclampsia, these proteins are produced in excess and they largely contribute to proteinuria and glomerular endotheliosis (swollen cytoplasm of endothelial cells). During normal pregnancies, sFlt-1 increases from 29 weeks of gestation to term [5], and albuminuria also increases [6], to a much lesser extent than in preeclampsia, but in proportions closely correlated with concentrations of sFlt-1 in the maternal blood [7]. Thus, while the physiological increase in albuminuria in the first trimester of pregnancy is explained by hyperfiltration [6], a second increase occurs during the third trimester, probably because of endotheliosis: Indeed, in 2003 a report by 
Strevens et al. established that healthy pregnant volunteers, subjected to a kidney biopsy at the end of their gestation, may also have mild endotheliosis [8]. From a renal perspective, normal pregnancy and preeclampsia are not separated by a clear line of demarcation, and are rather a continuum. Representative images of glomerular endotheliosis are shown in Fig. 1a, b.

Full blown endotheliosis may lead to nephrotic-range proteinuria. It is reasonable to assume that glomerular endotheliosis may also contribute to tubular hypoxia, because glomerular capillaries eventually give rise to capillaries- the vasa recta-that provide oxygen to the tubules. The third segment of the proximal tubule, also known as the pars recta, is located at the junction between the cortex and the medulla of the kidney, where oxygen tension $\left(\mathrm{PO}_{2}\right)$ is physiologically low (10-20 $\mathrm{mmHg}$, as opposed to $40-50$ in the cortex) while energetic consumption is high [9]. Although human red blood cells are to some extent deformable, a decrease in the capillary lumen-such as seen during endotheliosis - will undoubtedly impair their flow. Overall, this probably explains why, regardless of the obstetric circumstance causing AKI (c.f. Fig. 1c), (ischemic) acute
Fig. 1 Endotheliosis is defined by endothelial changes in renal glomeruli, combined with swollen endothelial cells leading to narrowed capillary lumen $(\mathbf{a}, \mathbf{b})$. There is a continuum between normal pregnancy and preeclampsia as far as these endothelial changes are concerned. In many cases of post-partum AKI, acute tubular necrosis is seen (c). Electronic microscopy is the best method to objectivize endothelial changes (d)
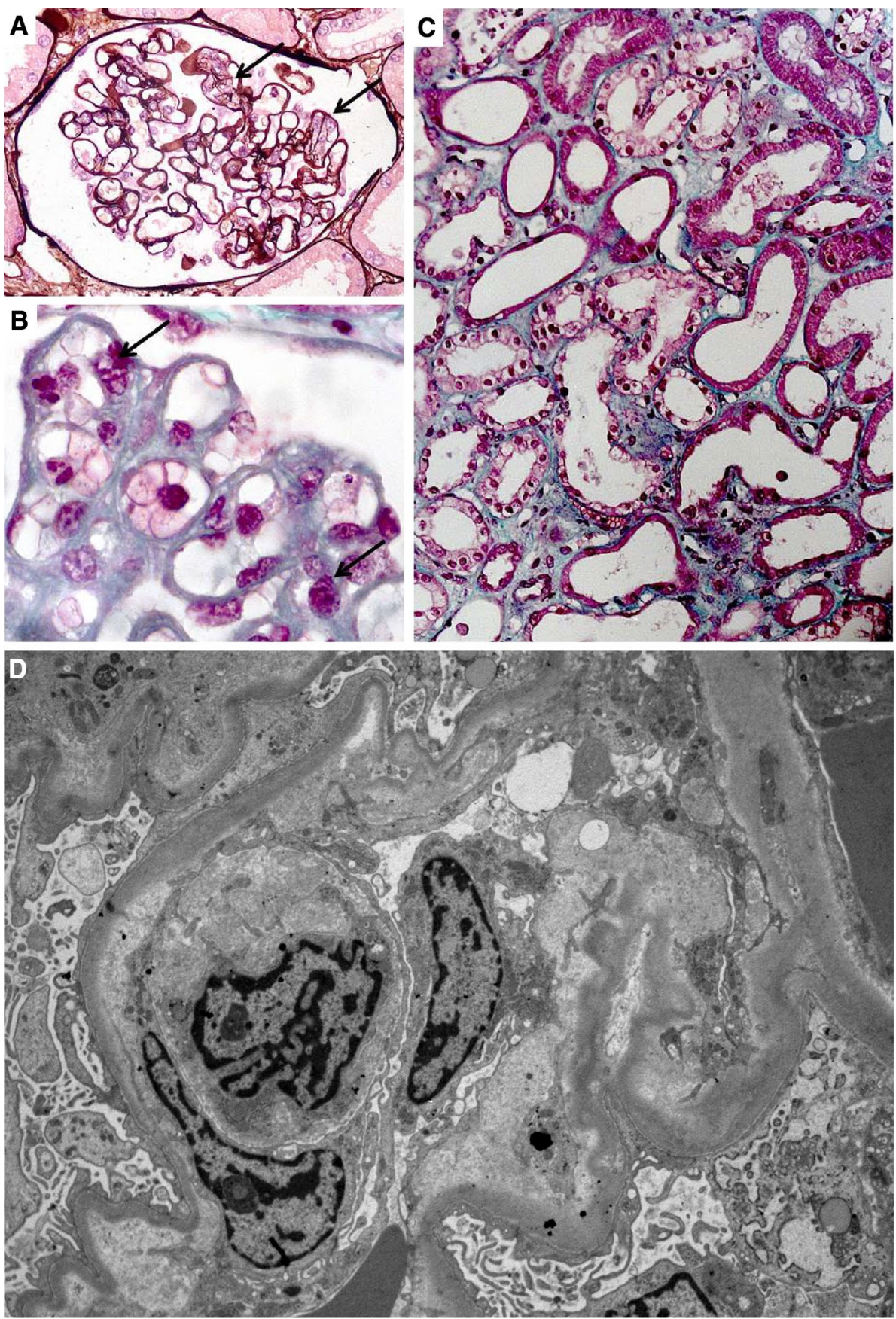
tubular necrosis (ATN) is often the predominant lesion seen in post-partum kidney biopsies [10-12]. If severe, preeclampsia alone is sufficient to induce ATN [12]. A further insult is constituted if blood loss occurs due to post-partum haemorrhage (for instance, a 40\% blood loss makes the $\mathrm{PO}_{2}$ drop as low as $8-12 \mathrm{~mm} \mathrm{Hg} \mathrm{[13]).} \mathrm{Overall,} \mathrm{in} \mathrm{the} \mathrm{kidney} \mathrm{a}$ gravid endothelium probably increases the vulnerability of proximal tubules, and specific complications such as preeclampsia, post-partum haemorrhage or hypotension will precipitate renal failure. Consequences are particularly tragic in poor income countries $[14,15]$.

\section{Challenges in the early definition of peripartum AKI}

A general definition of AKI (outside of the context of pregnancy) has been available since 2011 [16]. It is based on the degree of increase in serum creatinine, or of decrease in urinary output (Table 1). Any serum creatinine increase of $>0.3 \mathrm{mg} / \mathrm{dl}$, or a urinary output $<0.5 \mathrm{ml} / \mathrm{kg} / \mathrm{h}$ over $6 \mathrm{~h}$, is now sufficient to define AKI stage 1. Is this "dynamic" definition appropriate in the setting of pregnancy? The absolute value of creatinine is indeed an unsatisfactory measure because both hyper-filtration, which settles in the first weeks of gestation, and haemodilution, decrease the concentration of creatinine in the serum [17]. Thus, despite intrinsic variability of the different biochemical tests, and while the absolute value of serum creatinine may be decreased physiologically in pregnancy, an increase above baseline remains of interest (of note, hyperfiltration is attenuated in the last phases of pregnancy). However, glomerular filtration returns to baseline and serum creatinine increases in the immediate post-partum, returning to pre-pregnancy values within

Table 1 Definition of AKI according to the 2011 kidney disease/ improving global outcome (KDIGO) guidelines

\begin{tabular}{lll}
\hline Stage & Serum creatinine & Urinary output \\
\hline 1 & $1.5-1.9$ times baseline & $<0.5 \mathrm{ml} / \mathrm{kg} / \mathrm{h}$ for $6-12 \mathrm{~h}$ \\
& OR & \\
& $\geq 0.3 \mathrm{mg} / \mathrm{dl}(\geq 26.5 \mu \mathrm{mol} / \mathrm{l})$ & \\
& increase & \\
2 & $2.0-2.9$ times baseline & $<0.5 \mathrm{ml} / \mathrm{kg} / \mathrm{h}$ for $\geq 24 \mathrm{~h}$ \\
3 & 3.0 times baseline & $<0.3 \mathrm{ml} / \mathrm{kg} / \mathrm{h}$ for $\geq 24 \mathrm{~h}$ \\
& OR & OR \\
& Increase in serum creatinine to & Anuria for $\geq 12 \mathrm{~h}$ \\
& $\geq 4.0 \mathrm{mg} / \mathrm{dl}(\geq 353.6 \mu$ mol $/ \mathrm{l})$ & \\
& OR & \\
& Initiation of renal replacement & \\
therapy & \\
OR, in patients $<18$ years, decrease & \\
in eGFR to $<35 \mathrm{ml} / \mathrm{min}$ per & \\
& & \\
& & \\
\end{tabular}

$e G F R$ estimated glomerular filtration rate
2 weeks following delivery, thus making early diagnosis of post partum AKI occasionally challenging [17, 18].

A similar course has been observed in women with preeclampsia, even though physiological hyper-filtration is usually less intense in this group [19].

\section{Circumstances of post-partum AKI}

\section{Post-partum haemorrhage}

Post-partum haemorrhage represents a classical primum movens for AKI, being a classical cause of acute tubular necrosis. The incidence had been decreasing at least in high-income countries until recently, when the use of procoagulant and anti-fibrinolytic agents such as tranexamic acid (sometimes used at up to $10 \mathrm{~g}$ in several hours) has been associated with the resurgence of renal cortical necrosis in France [20]. It is long known that kidneys from gravid mammals are exceptionally susceptible to coagulation [21]. Thus, a single injection of lipopolysaccharide induces renal cortical necrosis in gravid rabbits, while it generally takes two injections in non-gravid animals [22]. Used at low dose (1-2 g total) in a recent international trial enrolling women with post-partum haemorrhage, however, the use of tranexamic acid was reported to be safe [23]. Since its elimination depends on glomerular filtration (the molecular weight of tranexamic acid is $157 \mathrm{Da}$ ), we would like to underline the importance of a cautious use in the case of oliguria. Overall, even though ATN is the most probable cause of AKI, it is of the utmost importance to rapidly rule out a diagnosis of cortical necrosis in the aftermath of a post-partum haemorrhage if tranexamic acid or pro-coagulant factors (such as fibrinogen, or recombinant factor VII) have been employed, a fortiori if a disseminated intravascular coagulation has been noted. In contrast to ATN, which typically resolves in 2-3 weeks, cortical necrosis, whilst also ischemic in origin, is irreversible. Magnetic resonance imaging (MRI), especially T2-weighted and gadolinium contrastenhanced T1-weighted acquisitions, is now the gold standard for diagnosis, showing bilateral lack of cortical enhancement involving the cortex at the arterial excretory phase (c.f. Fig. 2) $[24,25]$. However, MRI may overestimate the spread of necrosis, and prognostic information should be provided with caution [20]. Contrast-enhanced ultrasound seems equally sensitive [26], but no large series are available.

\section{Preeclamptic syndromes}

Renal function is usually "abnormally normal" in women developing preeclampsia: hyperfiltration is less intense, and consequently serum creatinine is not as low as during normal pregnancy $[19,27]$. Here again glomerular 
Fig. 2 MRI T1 weighted with gadolinium contrast. When compared to the normal aspect of the kidney (a), renal cortical necrosis is characterized by the absence of enhanced contrast in the cortex (b). MRI magnetic resonance imaging
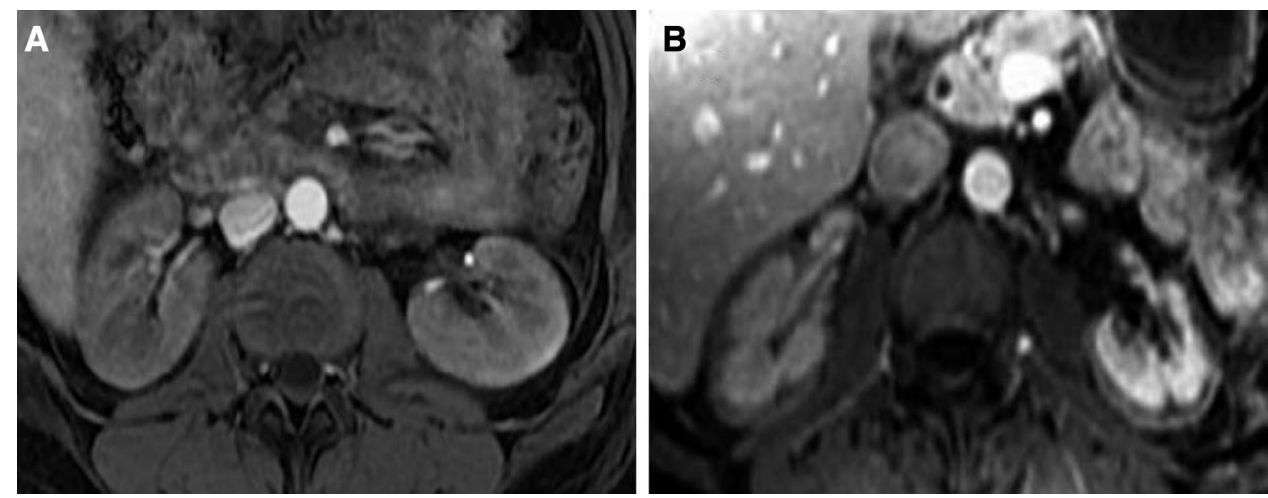

endotheliosis probably abrogates the capacity to maintain pregnancy-related hyperfiltration [28]. In severe cases, AKI may occur $[12,29]$, but attributing AKI to preeclampsia requires first to ascertain the diagnosis of preeclampsia and, second, to rule out differential diagnoses. Diagnosis of preeclampsia, a heterogeneous syndrome, can be supported by the measurement of sFlt- 1 and PlGF in maternal serum [30], but at present it is still essentially clinical (onset of hypertension and proteinuria after 20 weeks of gestation), including in the latest definition [31]. The relationship between the degree of endotheliosis and of proteinuria is not clear and, from an ethical point of view, preeclampsia is not an indication for a kidney biopsy (it is generally performed in cases where an underlying disease such as focal and segmental glomerulosclerosis, or IgA nephropathy, is suspected). Thus, the definition of the glomerular lesions independently associated with preeclampsia is difficult if not impossible. Still, severe endotheliosis is probably sufficient to induce ATN [12], through the impairment of the blood flow in glomerular capillaries and downstream. Mild endotheliosis is also present in the kidneys from healthy pregnant women [8]: any second hit (pro-ischemic) could thus precipitate ATN. Importantly, the underlying maternal condition could also be at stake: a chronic vascular disease preceding the pregnancy, such as diabetes or hypertension, would be an additional facilitating factor for tubular injury (in so called maternal, as opposed to placental, preeclampsia) [32].

The measure of low-molecular weight proteins in urine is non-invasive and may be informative with regard to tubular damage: retinol-binding protein (RBP), a small protein produced by the liver, is normally reabsorbed by the proximal tubule $[33,34]$. Urinary RBP will increase if an ischemic injury has led to ATN and can be similarly expressed as a ratio, over urinary creatinine, in a spot sample. RBP urinary concentration has been reported to be increased in preeclamptic patients [33]. Urinary alpha 1 microglobulin, another marker of tubular injury, has also been found a promising biomarker in the setting of normal or complicated pregnancies [35].

\section{Thrombotic microangiopathy}

Thrombotic microangiopathy (TMA) is one of the most important conditions to be considered in the differential diagnosis of AKI in pregnancy. The renal endothelial bed is the main victim of haemolytic and uremic syndrome (HUS), whether caused by shigatoxins (typical HUS), or by a genetically determined over-activation of the complement alternative pathway (atypical HUS). The cerebral endothelial bed is particularly affected during the thrombotic thrombocytopenic purpura (TTP), caused by a deficiency in ADAMTS-13 activity (ADAMTS-13 is the protease that cleaves multimers of the von Willebrand factor). Furthermore, the liver endothelial bed can be severely injured by the anti-angiogenic factors produced by placentae from preeclamptic women (sFlt-1 and sEng seem to act synergistically to induce HELLP [haemolysis, elevated liver-enzymes, and low platelets] syndrome) [2,36].

During pregnancy, it may be extremely complicated to distinguish preeclampsia (and HELLP syndrome) from a flare of TMA due to TTP or HUS, all the more since atypical HUS (aHUS) frequently occurs in the post-partum period and may also cause hypertension, proteinuria and AKI [37]. Since an increase in aspartate aminotransferase is not specific to liver injury, the differential diagnosis may be a real challenge. A common syllogism is to infer AKI due to a renal localization of TMA when patients develop HELLP syndrome. During the classical HELLP syndrome, the thrombotic microangiopathy is limited to the liver [38]. Although a French study had suggested that HELLP syndrome was frequently associated with genetic mutations in the alternate complement pathway, this was not confirmed by an Italian study published later [39, 40]. The role of variants (not mutants) is debatable, but HELLP and HUS are likely to be different entities.

Although renal TMA has been reported in preeclampsiarelated AKI, such cases are rare: during preeclampsia the activation of the coagulation in the kidney is typically limited to sub-endothelial fibrin deposition, that regresses after delivery [41]. In many cases, it is the persistence of TMA 
features after delivery that should compel the clinician to consider aHUS or TTP. Here, the main difficulty is to decide how much time a woman with isolated preeclampsia reasonably needs to recover from HELLP-related TMA. Studies are needed to address this major issue, limiting invasive or costly procedures, such as plasma exchanges or eculizumab.

\section{Acute fatty liver of pregnancy}

Acute fatty liver of pregnancy is a rare condition occasionally associated with AKI. Here again, ATN is the predominant lesion and can be explained by the additive effect of severe hyper-bilirubinaemia, now a recognized cause of tubular injury, and accumulation of lipids within tubular epithelial cells [42]. The latter is, however, debatable as a primary cause: experimentally, it is possible to induce an isolated overload of fatty acids in tubular epithelial cells without inducing AKI [43].

\section{Amniotic fluid embolism}

AKI due to ATN is one feature of amniotic fluid embolism, an often fatal condition causing multi-organ failure. In addition, amniotic debris have been reported to occlude renal vessels, which implies that debris reach the left ventricle via veins or a patent foramen ovale. Autopsy findings have indeed demonstrated the presence of amniotic emboli (acellular debris) in many organs, including the kidney, where they may advance as far as the glomerular tuft [44].

\section{Septic abortion}

Clostridium perfringens is a gram-positive bacterium and a saprophytic organism of the human vaginal flora found in an estimated $20 \%$ of women. As with other members of the genus Clostridium, it produces a highly dangerous toxin. In the case of a septic abortion (very rarely, in the aftermath of a normal delivery), C. perfringens bacteraemia may rapidly induce severe shock with disseminated intravascular coagulation and renal cortical necrosis [45]. In that case, in contrast to sepsis-related AKI, renal failure is typically irreversible. As explained previously, MRI or contrast-enhanced ultrasounds are helpful for diagnosis.

\section{Urological disorders}

When AKI develops after obstetrical surgery, it is cautious to rule out an unintentional ureteral ligature or a wound in the bladder or ureters causing a urinary leak. Both these conditions are typically painful, but pain may be considered a normal side effect of surgery, and imaging is needed to rule out this complication, especially if surgery was performed in the context of a life-threatening condition such as postpartum haemorrhage.

\section{Conclusions}

AKI is a rare but potentially severe complication of different conditions occurring during pregnancy, in particular in the last phases and post-partum. The obstetrician and the nephrologist should be aware of the extreme sensitivity of the tubular epithelium to hypoxia, exacerbated at the end of pregnancy by the abundant concentration of anti-angiogenic factors produced by the placenta.

Funding This work received no financial support.

\section{Compliance with ethical standards}

Conflict of interest The authors report no conflicts of interest.

\section{References}

1. Maynard SE, Min J-Y, Merchan J, Lim K-H, Li J, Mondal S et al (2003) Excess placental soluble fms-like tyrosine kinase 1 (sFlt1) may contribute to endothelial dysfunction, hypertension, and proteinuria in preeclampsia. J Clin Invest 111(5):649-658

2. Venkatesha S, Toporsian M, Lam C, Hanai J, Mammoto T, Kim YM et al (2006) Soluble endoglin contributes to the pathogenesis of preeclampsia. Nat Med 12(6):642-649

3. Eremina V, Jefferson JA, Kowalewska J, Hochster H, Haas M, Weisstuch J et al (2008) VEGF inhibition and renal thrombotic microangiopathy. N Engl J Med 358(11):1129-1136

4. Eremina V, Sood M, Haigh J, Nagy A, Lajoie G, Ferrara N et al (2003) Glomerular-specific alterations of VEGF-A expression lead to distinct congenital and acquired renal diseases. J Clin Invest 111(5):707-716

5. Levine RJ, Maynard SE, Qian C, Lim K-H, England LJ, Yu KF et al (2004) Circulating angiogenic factors and the risk of preeclampsia. N Engl J Med 350(7):672-683

6. Taylor AA, Davison JM (1997) Albumin excretion in normal pregnancy. Am J Obstet Gynecol 177(6):1559-1560

7. Yoshimatsu J, Matsumoto H, Goto K, Shimano M, Narahara H, Miyakawa I (2006) Relationship between urinary albumin and serum soluble fms-like tyrosine kinase 1 (sFlt-1) in normal pregnancy. Eur J Obstet Gynecol Reprod Biol 128(1-2):204-208

8. Strevens H, Wide-Swensson D, Hansen A, Horn T, Ingemarsson I, Larsen S et al (2003) Glomerular endotheliosis in normal pregnancy and pre-eclampsia. BJOG Int J Obstet Gynaecol 110(9):831-836

9. Aukland K, Krog J (1960) Renal oxygen tension. Nature 188:671

10. Sheikh IA, Shaheen FA (1998) Acute renal failure and HELLP syndrome: a single center's experience. Saudi J Kidney Dis Transpl Off Publ Saudi Cent Organ Transplant Saudi Arab 9(3):290-293

11. Abraham KA, Kennelly M, Dorman AM, Walshe JJ (2003) Pathogenesis of acute renal failure associated with the HELLP syndrome: a case report and review of the literature. Eur J Obstet Gynecol Reprod Biol 108(1):99-102

12. Sibai BM, Villar MA, Mabie BC (1990) Acute renal failure in hypertensive disorders of pregnancy. Pregnancy outcome and 
remote prognosis in thirty-one consecutive cases. Am J Obstet Gynecol 162(3):777-783

13. Nelimarkka O, Halkola L, Niinikoski J (1982) Distribution of renal cortical and Medullary tissue oxygenation in hemorrhagic shock. Acta Chir Scand 148(3):213-219

14. Ibarra-Hernández M, Orozco-Guillén OA, de la Alcantar-Vallín ML, Garrido-Roldan R, Jiménez-Alvarado MP, Castro KB et al (2017) Acute kidney injury in pregnancy and the role of underlying CKD: a point of view from México. J Nephrol 30(6):773-780

15. Fakhouri F, Deltombe C (2017) Pregnancy-related acute kidney injury in high income countries: still a critical issue. J Nephrol 30(6):767-771

16. Abstract (2012) Kidney Int Suppl 2(1):6

17. Odutayo A, Hladunewich M (2012) Obstetric nephrology: renal hemodynamic and metabolic physiology in normal pregnancy. Clin J Am Soc Nephrol CJASN 7(12):2073-2080

18. Hladunewich MA, Lafayette RA, Derby GC, Blouch KL, Bialek JW, Druzin ML et al (2004) The dynamics of glomerular filtration in the puerperium. Am J Physiol Renal Physiol 286(3):F496-503

19. Pritchard JA, Cunningham FG, Pritchard SA (1984) The Parkland Memorial Hospital protocol for treatment of eclampsia: evaluation of 245 cases. Am J Obstet Gynecol 148(7):951-963

20. Frimat M, Decambron M, Lebas C, Moktefi A, Lemaitre L, Gnemmi V et al (2016) Renal cortical necrosis in postpartum hemorrhage: a case series. Am J Kidney Dis Off J Natl Kidney Found

21. Wong TC (1962) A study on the generalized Shwartzman reaction in pregnant rats induced by bacterial endotoxin. Am J Obstet Gynecol 84:786-797

22. Apitz K (1934) Die Wirkung bakterieller kulturfiltrate nach umstimmung des gesamten endothels beim kanichen. Virchows Arch 1-33

23. WOMAN Trial Collaborators (2017) Effect of early tranexamic acid administration on mortality, hysterectomy, and other morbidities in women with post-partum haemorrhage (WOMAN): an international, randomised, double-blind, placebo-controlled trial. Lancet Lond Engl 389(10084):2105-2116

24. Jeong JY, Kim SH, Sim JS, Lee HJ, Do K-H, Moon MH et al (2002) MR findings of renal cortical necrosis. J Comput Assist Tomogr 26(2):232-236

25. François M, Tostivint I, Mercadal L, Bellin MF, Izzedine H, Deray G (2000) MR imaging features of acute bilateral renal cortical necrosis. Am J Kidney Dis Off J Natl Kidney Found 35(4):745-748

26. McKay H, Ducharlet K, Temple F, Sutherland T (2014) Contrast enhanced ultrasound (CEUS) in the diagnosis of post-partum bilateral renal cortical necrosis: a case report and review of the literature. Abdom Imaging 39(3):550-553

27. Assali NS, Kaplan SA, Fomon SJ, Douglass RA (1953) Renal function studies in toxemia of pregnancy; excretion of solutes and renal hemodynamics during osmotic diuresis in hydropenia. J Clin Invest 32(1):44-51

28. Lafayette RA, Druzin M, Sibley R, Derby G, Malik T, Huie P et al (1998) Nature of glomerular dysfunction in pre-eclampsia. Kidney Int 54(4):1240-1249

29. Prakash J, Ganiger VC, Prakash S, Iqbal M, Kar DP, Singh U et al (2018) Acute kidney injury in pregnancy with special reference to pregnancy-specific disorders: a hospital based study (2014-2016). J Nephrol 31(1):79-85
30. Zeisler H, Llurba E, Chantraine F, Vatish M, Staff AC, Sennström $M$ et al (2016) Predictive value of the sFlt-1:PlGF ratio in women with suspected preeclampsia. N Engl J Med 374(1):13-22

31. American College of Obstetricians and Gynecologists (2013) Task Force on Hypertension in Pregnancy. Hypertension in pregnancy. Report of the American College of Obstetricians and Gynecologists' Task Force on Hypertension in Pregnancy. Obstet Gynecol 122(5):1122-1131

32. Piccoli GB, Cabiddu G, Castellino S, Gernone G, Santoro D, Moroni $\mathrm{G}$ et al (2017) A best practice position statement on the role of the nephrologist in the prevention and follow-up of preeclampsia: the Italian study group on kidney and pregnancy. J Nephrol 30(3):307-317

33. Xiao J, Niu J, Ye X, Yu Q, Gu Y (2013) Combined biomarkers evaluation for diagnosing kidney injury in preeclampsia. Hypertens Pregnancy 32(4):439-449

34. Sass N, Facca TA, Pereira ARPR., Famá EA, Nishida SK, Moreira SR et al (2012) PP019 The role of renal markers in women with and without preeclampsia: evaluation of urinary excretion of podocytes and proteins. Pregnancy Hypertens 2(3):251-252

35. Codsi E, Garovic VD, Gonzalez-Suarez ML, Milic N, Borowski $\mathrm{KS}$, Rose $\mathrm{CH}$ et al (2017) Longitudinal characterization of renal proximal tubular markers in normotensive and preeclamptic pregnancies. Am J Physiol Regul Integr Comp Physiol 312(5):R773-R778

36. George JN, Nester CM (2014) Syndromes of thrombotic microangiopathy. N Engl J Med 371(7):654-666

37. Fakhouri F, Roumenina L, Provot F, Sallée M, Caillard S, Couzi L et al (2010) Pregnancy-associated hemolytic uremic syndrome revisited in the era of complement gene mutations. J Am Soc Nephrol JASN 21(5):859-867

38. Hecht JL, Ordi J, Carrilho C, Ismail MR, Zsengeller ZK, Karumanchi SA et al (2017) The pathology of eclampsia: an autopsy series. Hypertens Pregnancy 5:1-10

39. Fakhouri F, Jablonski M, Lepercq J, Blouin J, Benachi A, Hourmant $\mathrm{M}$ et al (2008) Factor $\mathrm{H}$, membrane cofactor protein, and factor I mutations in patients with hemolysis, elevated liver enzymes, and low platelet count syndrome. Blood 112(12):4542-4545

40. Crovetto F, Borsa N, Acaia B, Nishimura C, Frees K, Smith RJH et al (2012) The genetics of the alternative pathway of complement in the pathogenesis of HELLP syndrome. J Matern-Fetal Neonatal Med Off J Eur Assoc Perinat Med Fed Asia Ocean Perinat Soc Int Soc Perinat Obstet 25(11):2322-2325

41. Fisher KA, Luger A, Spargo BH, Lindheimer MD (1981) Hypertension in pregnancy: clinical-pathological correlations and remote prognosis. Medicine (Baltimore) 60(4):267-276

42. Slater DN, Hague WM (1984) Renal morphological changes in idiopathic acute fatty liver of pregnancy. Histopathology 8(4):567-581

43. Kang HM, Ahn SH, Choi P, Ko Y-A, Han SH, Chinga F et al (2015) Defective fatty acid oxidation in renal tubular epithelial cells has a key role in kidney fibrosis development. Nat Med 21(1):37-46

44. Liban E, Raz S (1969) A clinicopathologic study of fourteen cases of amniotic fluid embolism. Am J Clin Pathol 51(4):477-486

45. Pritchard JA, Whalley PJ (1971) Abortion complicated by Clostridium perfringens infection. Am J Obstet Gynecol 111(4):484-492 